See discussions, stats, and author profiles for this publication at: https://www.researchgate.net/publication/307577124

\title{
Pereskia aculeata Miller Flour: Metabolic Effects and Composition
}

Article in Journal of Medicinal Food · September 2016

DOI: 10.1089/jmf.2016.0052

CITATIONS

4

12 authors, including:

Sandra Maria Barbalho

Universidade de Marília - Medicina

98 PUBLICATIONS 417 CITATIONS

SEE PROFILE

Patricia Bueno

U.- Universidade de Marília

29 PUBLICATIONS 39 CITATIONS

SEE PROFILE

Some of the authors of this publication are also working on these related projects:

Project Metabolic profile View project

Project Homeopathy View project
READS

196

Elen Landgraf Guiguer

Universidade de Marília

53 PUBLICATIONS 247 CITATIONS

SEE PROFILE 


\title{
Pereskia aculeata Miller Flour: Metabolic Effects and Composition
}

\author{
Sandra Maria Barbalho,,2 Élen Landgraf Guiguer,, ${ }^{1,2}$ Paulo Sérgio Marinelli,, \\ Patrícia Cincotto do Santos Bueno, Leticia Maria Pescinini-Salzedas, \\ Mirele Cristine Batista dos Santos, ${ }^{1}$ Marie Oshiiwa, Claudemir Gregório Mendes, \\ Manoel Lima de Menezes, Cláudia Cristina Teixeira Nicolau, \\ Alda Maria Otoboni, and Ricardo de Alvares Goulart ${ }^{4}$ \\ ${ }^{1}$ Department of Biochemistry and Pharmacology, School of Medicine, University of Marília (UNIMAR), Marília, Brazil. \\ ${ }^{2}$ Department of Biochemistry and Nutrition, Faculty of Food Technology of Marília (FATEC), Marília, Brazil. \\ ${ }^{3}$ Faculty of Sciences-UNESP, Bauru, Brazil. \\ ${ }^{4}$ Department of Gastroenterology, Hospital of the University of Marília (UNIMAR), Marília, Brazil.
}

\begin{abstract}
Pereskia aculeata Miller is known in Brazil as ora-pro-nobis (OPN) and has been used commonly in the folklore medicine. The purpose of our study was to evaluate the composition and the effects of OPN flour on the metabolic profile and intestinal motility of Wistar rats. Animals were divided randomly into five groups $(n=10)$ : G1 (control group) and G2 (treated with OPN flour). For the intestinal motility: G3 (control group), G4 (treated with senne), and G5 (treated with OPN flour). After 40 days, G1 and G2 were euthanized and metabolic profiles were analyzed (glycemia, cholesterol, triglycerides, high density lipoprotein [HDL-c], C reactive protein, AST, ALT, Lee Index, weight, and visceral fat). The flour of OPN was effective in reducing percentage of weight gain, visceral fat, levels of total cholesterol, triglycerides, low density lipoprotein, very low density lipoprotein, and increased HDL-c. Significance was also found in the distance covered by the activated charcoal from the pylorus to the beginning of the cecum, which was higher in animals treated with OPN. Our results indicate that OPN flour may bring health benefits, as the improvement of the intestinal motility, and it is associated with reduction of visceral fat and lipid profile, as well as the increase of HDL-c levels. With these results, we may suggest that the incorporation of this flour in different industrial products may be a convenient and effective way for the intake of healthier products.
\end{abstract}

KEYWORDS: $\bullet$ cholesterol $\bullet$ glycemia $\bullet$ intestinal motility $\bullet$ Pereskia aculeata $\bullet$ visceral fat $\bullet$ wistar rats

\section{INTRODUCTION}

$\mathbf{N}$ ON-COMMUNICABLE CHRONIC diseases such as diabetes (DM), metabolic syndrome (MS), and cardiovascular diseases (CVD) are among the leading causes of death in the modern societies. These diseases are associated with dyslipidemia, obesity, and insulin resistance arising from changes in lifestyle and physical inactivity. ${ }^{1-3}$

Plants may be used in popular medicine for prevention or help in the treatment of these diseases and many studies have been designed to evaluate the actual effects in health promotion or prevention of risk factors. ${ }^{4-6}$

Pereskia aculeata Miller belongs to the Cactaceae family and is popularly known in Brazil as ora-pro-nobis (OPN). The leaves are good source of calcium, magnesium, manganese, zinc, and rich in dietary fiber and arabinogalactan content,

Manuscript received 3 April 2016. Revision accepted 5 July 2016.

Address correspondence to: Sandra Maria Barbalho, PhD, Department of Biochemistry and Pharmacology, School of Medicine, University of Marilia, Av. Higino Muzzi Filho 1001, Marília 15525-902,SP,Brazil,E-mail: smbarbalho@gmail.com which make it an agriculturally and economically important food source. It also contains vitamin $\mathrm{C}$ and folic acid and a high content of amino acids, mainly tryptophan. ${ }^{7-10}$

This plant has been described as possessing antiinflammatory and antinociceptive effects and compounds as di-tert-butylphenol isomers, tryptamine, mescaline, petunidin, hordenine, abrine, and quercetin were identified in its leaves. Besides being used as food by poor people, it is also used in popular medicine as laxative, emollients, and to treat skin wounds and inflammation. ${ }^{11,12}$

The use of plants for functional purposes in production of processed products can be a viable and easy option for prevention of diseases. The production of functional flours is useful since different products nutritionally enriched can be developed. Furthermore, products commonly acquired by consumers or products enjoyed by children can be quick and easy alternatives to improve the nutritional value of meals. With this worry, we aimed to verify in this study, the effects of Pereskia aculeata (OPN) flour on the metabolic profile and in the intestinal motility of Wistar rats, as well as to study its composition. 


\section{MATERIAL AND METHODS}

\section{Preparation of the OPN flour}

Pereskia aculeata Miller leaves were removed from the branches and rinsed in distilled water and immersed in a solution of $200 \mathrm{~mL}$ of sodium hypochlorite distilled water (1:1) and later dehydrated in a ventilated oven at a temperature of $60^{\circ} \mathrm{C}$ for $24 \mathrm{~h}$. Then the material was crushed in the mill (Model MA090- Marconi ${ }^{\circledR}$ ), screened at 60 mesh sieve, and the flour obtained was wrapped in glasses with airtight lids.

\section{Preparation of the supplemented rat feed}

The rat feed was prepared weekly, in a proportion of $30 \%$ and $70 \%$ flour/commercial feed: the commercial rat feed was crushed and mixed with the OPN flour. This mixture was molded and the resulting pellets were dried in an air circulating oven at $65^{\circ} \mathrm{C}$ for about $8 \mathrm{~h}$, stored in polyethylene packaging, and refrigerated at $5^{\circ} \mathrm{C}$ until its utilization.

\section{Ethical principles}

Throughout the experiment, the animals were fed and watered ad libitum and were cared for according to the recommendations of the Canadian Council's "Guide for the care and use of experimental animals." This research was approved by the Animal Research Ethics Committee of the University of Marília, protocol 90/2013 (UNIMAR/Marília, SP, Brazil).

\section{Animal groups}

Male Wistar rats with 230-250 g were kept in the vivarium at UNIMAR and housed in collective cages under a 12$\mathrm{h}$ dark/12-h light cycle, room temperature of $22^{\circ} \mathrm{C} \pm 2{ }^{\circ} \mathrm{C}$, and relative air humidity of $60 \% \pm 5 \%$. After a period of acclimation to laboratory conditions, the animals were divided randomly in the following experimental groups ( $n=10$ per group): $\mathbf{G 1}$ that was fed water and rat food $a d$ libitum (control group 1), and $\mathbf{G 2}$ that was fed water and rat food supplemented with OPN ad libitum.

The weight gain was evaluated once a week and the consumption of the animals was recorded based on the leftovers found each day.

\section{Blood collection and analysis}

After the experimental period (40 days), the animals were euthanized with a lethal intraperitoneal injection of thiopental $(200 \mathrm{mg} / \mathrm{Kg})$ until complete sedation. Immediately after death, blood samples were collected from the vena cava to evaluation of the biochemical profile: glycemia, triglycerides (TG), total cholesterol (TC), low density lipoprotein, very low density lipoprotein, high density lipoprotein (HDL-c), high sensitivity $\mathrm{C}$ reactive protein (hsCRP), aspartate aminotransferase (AST), and alanine aminotransferase (ALT). The glycemia, lipid profile, and hsCRP were measured in $\mathrm{mg} / \mathrm{dL}$ and AST and ALT in U/L.
Atherogenic index (AI) and protection index (PI) were calculated according to Schulpis, Karikas ${ }^{13}$ and Munshi, Joshi, Rane ${ }^{14}: \mathrm{AI}=(\mathrm{TC}-\mathrm{HDL}-\mathrm{c}) / \mathrm{HDL}-\mathrm{c}$. The PI is calculated as follows: $\{[\mathrm{AI}(\mathrm{G} 1)-\mathrm{AI}(\mathrm{G} 2)] / \mathrm{AI}(\mathrm{G} 1)\} \times 100$.

\section{Anthropometric parameters}

After euthanasia, the body weight and length were evaluated to determine the Lee index $=$ cube root of body weight $(\mathrm{g}) /$ nose-anus length $(\mathrm{cm})$ and the percentage of weight gain. Values above 0.3 indicate overweight. ${ }^{15,16}$ An incision was also made in the abdominal region and the visceral fat was removed and weighed.

\section{Intestinal motility test}

The intestinal motility test was evaluated according to the model described by Michelin, Salgado ${ }^{17}$ with modifications. Cassia angustifolia suspension was used as comparison for the results. After a 24-h fast, the control group and treated groups were gavage fed, according to: G3 that was treated with $0.2 \mathrm{~mL}$ of propylene glycol; G4 that was treated with $0.2 \mathrm{~mL}$ Cassia angustifolia (senne) suspension prepared with propylene glycol, $50 \mathrm{mg} / \mathrm{mL}$ (dose of $30 \mathrm{mg} / \mathrm{kg}$ ); and G5 that was treated with $0.2 \mathrm{~mL}$ of OPN flour suspension prepared with propylene glycol, $50 \mathrm{mg} / \mathrm{mL}$ (dose of $30 \mathrm{mg} / \mathrm{kg}$ ).

Forty-five minutes later, the groups were gavage fed $0.2 \mathrm{~mL}$ of a $10 \%$ activated charcoal suspension in 5\% gum arabic. Two hours after the administration of activated charcoal, the animals were euthanized with a lethal intraperitoneal injection of thiopental $(200 \mathrm{mg} / \mathrm{Kg})$. After death was confirmed, the intestines were removed and their length and the distance traveled by the activated charcoal were measured.

\section{Composition of the OPN flour and the rat feed}

The rat feed, OPN flour, and the rat feed added with OPN flour were evaluated in terms of its moisture content (total dry extract) using the gravimetric method in an oven at $105^{\circ} \mathrm{C}$ for $16 \mathrm{~h}$ until it reached a constant weight. Amount of lipids was evaluated by Soxhlet extraction. Total nitrogen was performed by the Kjeldahl method, multiplying the values of total nitrogen by 6.25 to obtain the equivalent values in protein. Ashes were analyzed in a muffle furnace at $550^{\circ} \mathrm{C}$, carbohydrates by difference, as well as crude fiber. ${ }^{18}$ All the analyses were performed in triplicate.

\section{Statistical analysis}

Kruskal-Wallis supplemented with Dunn test was used for the statistical analysis and the variables are presented as mean and standard error mean, adopting a 5\% level of significance.

\section{RESULTS}

In Table 1, we may observe that OPN decreased total lipids, weight gain, visceral fat, and Lee index and increased levels of HDL-c. OPN group presented an AI lower (Table 2) than the control and by calculating the percentage of 
Table 1. Mean and Standard Deviation of the Biochemical and Anthropometric Parameters IN The Control Group (G1) AND OPN Group (G2)

\begin{tabular}{lcc}
\hline Parameters & $G 1$ & $G 2$ \\
\hline Glycemia (mg/dL) & $138.73 \pm 55.79\left(\mathrm{~A}^{\mathrm{a}}\right)$ & $167.50 \pm 50.01(\mathrm{~A})$ \\
Total cholesterol (mg/dL) & $53.55 \pm 4.95(\mathrm{~B})$ & $47.00 \pm 6.38(\mathrm{~A})$ \\
Triglycerides (mg/dL) & $123.36 \pm 23.04(\mathrm{~B})$ & $44.30 \pm 12.61(\mathrm{~A})$ \\
HDL-c (mg/dL) & $32.64 \pm 2.62(\mathrm{~A})$ & $39.20 \pm 5.55(\mathrm{~B})$ \\
LDL-c (mg/dL) & $28.00 \pm 8.16(\mathrm{~B})$ & $15.70 \pm 4.79(\mathrm{~A})$ \\
VLDL-c (mg/dL) & $16.73 \pm 8.08(\mathrm{~B})$ & $9.20 \pm 3.05(\mathrm{~A})$ \\
hsPCR (mg/dL) & $0.07 \pm 0.03(\mathrm{~A})$ & $0.07 \pm 0.02(\mathrm{~A})$ \\
AST (U/L) & $117.27 \pm 29.08(\mathrm{~A})$ & $113.10 \pm 25.78(\mathrm{~A})$ \\
ALT (U/L) & $70.45 \pm 15.41(\mathrm{~A})$ & $76.6022 .61(\mathrm{~A})$ \\
Weight gain (g) & $65.82 \pm 6.82(\mathrm{~B})$ & $53.75 \pm 6.51(\mathrm{~A})$ \\
Weight of visceral fat (g) & $5.48 \pm 2.30(\mathrm{~B})$ & $2.17 \pm 0.88(\mathrm{~A})$ \\
Lee index (g/cm) & $0.286 \pm 0.007(\mathrm{~B})$ & $0.238 \pm 0.001(\mathrm{~A})$ \\
\hline
\end{tabular}

${ }^{a}$ Different letters indicate a significant difference between the treatments at a level of 5\%. LDL-c, low density lipoprotein; OPN, ora-pro-nobis; VLDL-c, very LDL; HDL-c, high density lipoprotein; hsPCR, high sensitivity protein C reactive; AST, aspartate aminotransferase; and ALT, alanine aminotransferase.

cardiovascular protection (PI), we found that this plant reduces the risk of cardiovascular disease by $67.1 \%$. Our results did not show significant differences in the food consumption among the groups (data not showed).

For the intestinal motility evaluation, significant differences were found among OPN group (G5) compared to senne group (G4) and control group (Table 3). The distance covered by the activated charcoal from the pylorus to the beginning of the cecum was higher in animals treated with OPN.

Table 4 shows that the rat feed mixed with OPN flour presented higher values of calories, carbohydrates, and total fat.

\section{DISCUSSION}

Obesity is related to several chronic degenerative disorders, as well as visceral fat that is related to the accumulation of fat mass in the abdominal area, and is considered a good predictor of CVD once it may promote deleterious effect on the metabolic and hemodynamic profile, and is related to glucose intolerance, insulin resistance, systemic arterial hypertension, and dyslipidemias. Lee index is an anthropometric parameter used to assess over weight and obesity in rats. ${ }^{15,16,19}$ Our results showed significant reduction of body weight gain visceral fat and Lee Index in animals treated with OPN flour although observing in Table 3 that the rat feed mixed with the OPN flour possesses an energy value higher than the regular rat feed. Furthermore,

Table 2. Mean and Standard Deviation of AI IN The Control Group (G1) AND OPN Group (G2)

\begin{tabular}{lcc}
\hline Parameters & $G 1$ & $G 2$ \\
\hline AI & $0.612(\mathrm{~B})$ & $0.192(\mathrm{~A})$ \\
\hline
\end{tabular}

AI, atherogenic index.
Table 3. Mean and Standard Deviation of the Distance Covered by the Activated Charcoal from the Pylorus to the Beginning of the Cecum

\begin{tabular}{l}
\hline$G 3 \quad G 4$ \\
\hline $73.79 \pm 8.13(\mathrm{~A}) \quad 84.54 \pm 5.55(\mathrm{~B})$ \\
\hline${ }^{\text {a Different letters indicate a significant difference between the treatments at }}$ \\
a level of 5\%. \\
G3, group treated with propylene glycol; G4, group treated with senne; and \\
G5, group treated with OPN.
\end{tabular}

by analyzing the AI (Table 1) and the PI, we may say that OPN exhibits a high index of heart protection. These results, together with the positive effects observed in the lipid profile, suggest that this flour may reduce the risk factors for obesity, DM, MS, and CVD.

Our search in the literature resulted in only one study where authors investigated the effects of OPN in the metabolic profile. This investigation was performed by Souza $e t$ $a .^{7}$ that evaluated the effects on the biochemical profile of Wistar rats and did not find significant modifications on the lipid profile after the treatment, except for increments in the HDL-c levels. They also did not find significant changes in the Lee Index, but observed significant reduction on the visceral fat gain in animals with regular diet.

Almeida, Corrêa ${ }^{11}$ showed that rats fed a hypercaloric diet that received Pereskia grandifolia flour showed more effectiveness in reducing weight gain and presented reduced body mass index, Lee index, glycemia, and lower levels of triglycerides. Authors concluded that daily consumption of this flour could prevent obesity and CVD.

CRP has been considered an inflammatory marker, which is normally regulated by cytokines as interleucin- 1 , IL- 6 , and tumor necrosis factor $\alpha$, and may be used for the initial detection of a low-grade inflammation condition. ${ }^{20,21}$ Our results did not show variations in animals treated with OPN flour.

Elevation in the blood levels of AST and ALT may indicate the destruction of liver cells. No significant alterations were observed in the group treated with OPN, suggesting that, for this parameter, this flour is safe for consumption. ${ }^{22}$

Table 4. Mean and Standard Deviation of the Composition of OPN Flour, Commercial Rat Feed, and Commercial Rat Feed (70\%) Mixed with OPN Flour (30\%)

\begin{tabular}{|c|c|c|c|}
\hline Samples & OPN flour & Rat feed & $\begin{array}{c}\text { Rat feed } \\
70 \%+O P N \\
\text { flour } 30 \%\end{array}$ \\
\hline Energy value (kcal) & $323.63 \pm 1.17$ & $350.06 \pm 1.15$ & $366.19 \pm 1.26$ \\
\hline $\begin{array}{l}\text { Moisture at } 105^{\circ} \mathrm{C} \\
(\% \mathrm{~m} / \mathrm{m})\end{array}$ & $5.90 \pm 0.09$ & $9.60 \pm 0.09$ & $1.01 \pm 0.04$ \\
\hline Ashes $(\% \mathrm{~m} / \mathrm{m})$ & $17.83 \pm 0.04$ & $7.32 \pm 0.14$ & $11.58 \pm 0.14$ \\
\hline arbohydrates $(\% \mathrm{~m} / \mathrm{m})$ & $48.39 \pm 0.96$ & $57.15 \pm 1.09$ & $64.59 \pm 0.44$ \\
\hline & 24.1 & $22.38=$ & $22.38 \pm 0.88$ \\
\hline Total fat $(\% \mathrm{~m} / \mathrm{m})$ & $3.71 \pm 0.16$ & $3.55 \pm 0.29$ & $5.31 \pm 0.23$ \\
\hline Crude fiber $(\% \mathrm{~m} / \mathrm{m})$ & $32.80 \pm 1.88$ & $7.04 \pm 0.08$ & $14.39 \pm 0.30$ \\
\hline
\end{tabular}


Some of the benefic effects of OPN may be attributed to the higher content of vitamin C, carotene, and fibers. Mercê et al. ${ }^{8}$ showed that the leaves of this plant have high content of fibers. Takeiti et al. ${ }^{9}$ also found high content of vitamin C in the leaves, as well as carotenoids. Souza et $a l .{ }^{23}$ studied essential oil from $P$. aculeate and found 30 components, but the most prevalent was oxygenated diterpenes. Some authors have shown that vitamin C, carotenoids, and fibers are associated with reduction of risk factors for MS, DM, and CVD. Vitamin C and carotenoids may act as antioxidants, thus reducing the effects of free radical and inflammation processes in the organism. As obesity, DM, and MS are related to oxidation and inflammation, we may suggest that the presence of antioxidants in the OPN flour is useful in preventing these chronic diseases. ${ }^{24,25}$

Acute evaluation of intestinal motility of the animals showed that this plant has potential to treat obstipation. Besides, during the 40 days of the experimental period, animals treated with OPN flour showed intestinal motility higher than the control and senne groups. Constipation may affect individuals at any age and can be described as one of the most prevalent disorders found by doctors and it is related to significant medical expenses and the negative interference in quality of life. Individuals more than 65 and women are usually more affected than men. There is a plethora of allopathic and nonallopathic medications available for the treatment of this condition; however, many are ineffective and have high cost. ${ }^{26,27}$ Many studies show that several plants may exhibit laxative effects and one of them is the well-known senne. Many compounds such as naphthalene, sennosides, anthraquinone, acetophenones, flavonoids, and xanthones in its leaves and pods can be associated to the increase in the intestinal motility. ${ }^{28,29}$ No studies in the literature were found to compare the effects of this plant in the gastrointestinal tract with our results.

\section{CONCLUSION}

Our results with the use of OPN flour are promising because they indicate that this product can bring health benefits, as the improvement of the intestinal motility, and is associated with reduction of visceral fat and lipid profile, as well as the increase of HDL-c levels. Thus, the incorporation of this flour in different industrial products may be a convenient and effective way for the intake of healthier products.

\section{AUTHOR DISCLOSURE STATEMENT}

No competing financial interests exist.

\section{REFERENCES}

1. Ingaramo RA: Obesity, diabetes, and other cardiovascular risk factors in native populations of South America. Curr Hypertens Rep 2016;18:9.

2. Castoldi A, Naffah de Souza C, Câmara NO, Moraes-Vieira PM: The macrophage switch in obesity development. Front Immunol 2016;6:637.
3. Yang HI, Kim HC, Jeon JY: The association of resting heart rate with diabetes, hypertension, and metabolic syndrome in the Korean adult population: The fifth Korea national health and nutrition examination survey. Clin Chim Acta 2016; pii: S00098981(16)30006-30007.

4. Barbalho SM, Bueno PC, Delazari DS, Guiguer EL, Coqueiro DP, Araújo AC, de Souza Mda S, Farinazzi-Machado FM, Mendes CG, Groppo M: Antidiabetic and antilipidemic effects of Manilkara zapota. J Med Food 2015;18:385-391.

5. Mans DR, Beerens T, Magali I, Soekhoe RC, Schoone GJ, Oedairadjsingh K, Hasrat JA, van den Bogaart E, Schallig HD: In vitro evaluation of traditionally used Surinamese medicinal plants for their potential anti-leishmanial efficacy. J Ethnopharmacol 2016; pii: S0378-8741(16)30012-30015.

6. Shayganni E, Bahmani M, Asgary S, Rafieian-Kopaei M: Inflammaging and cardiovascular disease: Management bymedicinal plants. Phytomedicine 2015; pii: S0944-7113(15)00356-6. Doi: 10.1016/j.phymed.2015.11.004.

7. Souza MSS, Barbalho SM, Guiguer EL, Araújo AC, Bueno PCS, Farinazzi-Machado FMV, Lima LML, Silva BC, Mendes CG: Effects of Pereskia aculeata miller on the biochemical profiles and body composition of wistar rats. J Biosci Med 2015;3:82-89.

8. Mercê ALR: Complexes of arabinogalactan of Pereskia aculeata and $\mathrm{Co} 2+, \mathrm{Cu} 2+, \mathrm{Mn} 2+$, and Ni2+. Bioresour Technol 2001;76:29-37.

9. Takeiti CY, Antonio GC, Motta EMP, Collares-Queiroz FP, Park KJ: Nutritive evaluation of non-conventional leafy vegetable (Pereskia aculeata Miller). Int J Food Sci Nutr 2009;60: $148-160$.

10. Pinto N de C, Duque AP, Pacheco NR, Mendes Rde F, Motta EV, Bellozi PM, Ribeiro A, Salvador MJ, Scio E: Pereskia aculeata: A plant food with antinociceptive activity. Pharm Biol 2015;53: 1780-1785.

11. Almeida MEF, Corrêa AD: Utilization of cacti of the genus Pereskia in the human diet in a municipality of minas gerais. Cienc Rural 2012;42:34-41.

12. Pinto NC, Machado DC, da Silva JM, Conegundes JL, Gualberto AC, Gameiro J, Moreira Chedier L, Castañon MC, Scio E: Pereskia aculeata Miller leaves present in vivo topical antiinflammatory activity in models of acute and chronic dermatitis. J Ethnopharmacol 2015;173:330-337.

13. Schulpis K, Karikas GA: Serum cholesterol and triglyceride distribution in 7767 school-aged Greek children. Pediatrics 1998;101:861-864.

14. Munshi RP, Joshi SG1, Rane BN. Development of an experimental diet model in rats to study hyperlipidemia andinsulin resistance, markers for coronary heart disease. Indian J Pharmacol 2014;46:270-276.

15. Bernardis LL, Patterson BD: Correlation between "Lee Index" and carcas fat content in weanling and adult female rats with hypothalamic lesions. J Endocrinol 1968;40:527-528.

16. Nery CS, Pinheiro IL, Muniz GS, Vasconcelos DAA, França SP, Nascimento E: Murinometric evaluations and feed efficiency in rats from reduced litter during lactation and submitted or not to swimming exercise. Rev Bras Med Esporte 2011;17:49-55.

17. Michelin DC, Salgado HRN: Evaluation of the laxative activity of Operculina macrocarpa L. Urban (Convolvulaceae). Rev Bras Farmacogn 2004;14:15-109.

18. IAL (Adolfo Lutz Institute-Sao Paulo): Physical and Chemical Methods for Food Analysis. Instituto Adolfo Lutz, Sao Paulo, Brasil, 2008. 
19. Park HR, Shin SR, Han AL, Jeong YJ: The correlation between the triglyceride to high density lipoprotein cholesterol ratio and computed tomography-measured visceral fat and cardiovascular disease risk factors in local adult male subjects. Korean J Fam Med 2015;36:335-340.

20. Zachariah JP, Hwang S, Hamburg NM, Benjamin EJ, Larson MG, Levy D, Vita JA, Sullivan LM, Mitchell GF, Vasan RS: Circulating adipokines and vascular function: Cross-sectional associations in a community-based cohort. Hypertension 2015; pii: Hypertensionaha.115.05949.

21. Furuhashi M, Saitoh S, Shimamoto K, Miura T: Fatty AcidBinding Protein 4 (FABP4): Pathophysiological insights and potent clinical biomarker of metabolic and cardiovascular diseases. Clin Med Insights Cardiol 2015;8(Suppl 3):23-33.

22. Cai C, Cao Z, Loughran PA, Kim S, Darwiche S, Korff S, Billiar TR: Mast cells play a critical role in the systemic inflammatory response and end-organ injury resulting from trauma. J Am Coll Surg 2011;213:604-615.

23. Souza LF, De Barros IB, Mancini E, De Martino L, Scandolera E, De Feo V: Chemical composition and biological activities of the essential oils from two Pereskia species grown in Brazil. Nat Prod Commun 2014;9:1805-1808.
24. Gregório BM, De Souza DB, de Morais Nascimento FA, Pereira LM, Fernandes-Santos C: The potential role of antioxidants in metabolic syndrome. Curr Pharm Des 2016;22:859-869.

25. Covarrubias-Pinto A, Acuña AI, Beltrán FA, Torres-Díaz L, Castro MA: Old things new view: Ascorbic acid protects the brain in neurodegenerative disorders. Int J Mol Sci 2015;16:28194-28217.

26. Hanif-Palla A, Gilani AH: Dual effectiveness of flaxseed in constipation and diarrhea: Possible mechanism. J Ethnopharmacol 2015; pii: S0378-8741(15)00223-00228.

27. Vandenplas Y, Alarcon P: Updated algorithms for managing frequent gastro-intestinal symptoms in infants. Benef Microbes 2015;6:199-208.

28. Seethapathy GS, Ganesh D, Santhosh Kumar JU, Senthilkumar U, Newmaster SG, Ragupathy S, Uma Shaanker R, Ravikanth G: Assessing product adulteration in natural health products for laxative yielding plants, Cassia, Senna, and Chamaecrista, in Southern India using DNA barcoding. Int J Legal Med 2015; 129:693-700.

29. Epifano F, Fiorito S, Locatelli M, Taddeo VA, Genovese S: Screening for novel plant sources of prenyloxyanthraquinones: Senna alexandrina Mill. and Aloe vera (L.) Burm. F. Nat Prod Res 2015;29:180-184. 